\title{
Essential oil of pataqueira (conobea scoparioides benth.): from natural occurrence and produced by hydroponics
}

\begin{abstract}
Conobea scoparioides (Scrophulariaceae) is a herbaceous species known as "pataqueira" occurring in wet areas of the Brazilian Amazon. The essential oil of "pataqueira" had a pleasant aroma and the main constituents analyzed by GC and GC-MS were methylthymol (40.0\%), thymol (38.5\%) and $\alpha$-phellandrene (12.9\%), comprising about $90 \%$ of the total oil. The economical exploitation of the plant has not been consolidated because it is an aquatic species with unfavorable cultivation during the dry season. In summertime, the plant vanishes from the wet areas and their seeds germinate again at the beginning of the rainy season. Based on this environmental condition, the plant was subjected to the NFT (nutrient film technique) hydroponic cultivation system, showing excellent adaptation. The species doubled in size after the first two months of cultivation reaching $30 \mathrm{~cm}$ and in four months it was growing to $85 \mathrm{~cm}$, providing $4 \mathrm{~kg} / \mathrm{m}^{2}$ of fresh biomass and oil yield of $3.2 \%$. It was estimated that $1000 \mathrm{~m}^{2}$ of hydroponic cultivation of C. scoparioides can produce $128 \mathrm{~kg}$ of oil in four months, or about $380 \mathrm{~kg}$ of oil per year in three annual crops.
\end{abstract}

Keywords: conobea scoparioides, scrophulariaceae, pataqueira, essential oil composition
Volume I Issue 3 - 2014

\author{
Rosilene G Costa,' Lenio Jose G de Faria,' \\ Sergio Antonio L de Gusmao, ${ }^{2}$ Joyce Kelly \\ $\mathrm{R}$ da Silva, ${ }^{3}$ Eloisa Helena A Andrade, ${ }^{4}$ Jose \\ Guilherme S Maia ${ }^{4,5}$ \\ 'Graduate Program in Chemical Engineering, Federal University \\ of Para, Brazil \\ ${ }^{2}$ Institute of Agricultural Sciences, Federal Rural University of \\ the Amazon, Brazil \\ ${ }^{3}$ Graduate Program in Biotechnology, Federal University of Para, \\ Brazil \\ ${ }^{4}$ Graduate Program in Chemistry, Federal University of Para, \\ Brazil \\ ${ }^{5}$ Graduate Program in Natural Resources from Amazon, Federal \\ University of Western Para, Brazil
}

\begin{abstract}
Correspondence: JGS Maia, Graduate Program in Chemistry, Federal University of Para, Rua Augusto Correa No. I, 66075I I 0 Belem, PA, Brazil, Tel +55-91-8I467067, Fax +55-91-
\end{abstract} 32353043,Email gmaia@ufpa.br

Received: May 23, 2014 | Published: July 15, 2014
Abbreviations: NFT, nutrient film technique; PM, mature plants; PH, plants grown hydroponically; UFRA, universidade federal rural da amazonia; MPEG, museu emilio goeldi; PNf, fresh plants from natural origin; PHf, fresh plants from hydroponics; RI, retention index; PNd, dried plants from natural origin; $\mathrm{PHd}$, dried plants from hydroponics; $\mathrm{PHb}$, dried plants from fixed bed dryer

\section{Introduction}

Conobea scoparioides (Cham. \& Schltdl) Benth (syn. Sphaerotheca scoparioides Cham. \& Schltdl.), belonging to Scrophulariaceae, is a herbaceous aromatic plant known as "pataqueira", with occurrence in the bed of small streams and wetlands of the Brazilian Amazon. It has sessile, opposite, lanceolate and serrated leaves, with square green stems and white bluish flowers (www.tropicos.org/ NAME/29200721). ${ }^{1}$ The Amazonian local people have used the plant for aromatic baths and in the treatment of avitaminosis B1.,

A previous work with "pataqueira" showed essential oil yield ranging from 1.5 to $3.0 \%$ and their main constituents were methylthymol, thymol and $\alpha$-phellandrene. ${ }^{4}$ Furthermore, the oil provided significant antioxidant activity. ${ }^{5}$ The international companies of cosmetics and fragrances have shown great interest in the marketing of the "pataqueira" oil, but its commercial exploitation is hindered by the inability to maintaining a production system in the wetlands of the region. Generally these areas are dry in summer. This species suffers from lack of water and will be missing for about 6 months. During the rainy season, the seeds sprout and the plant grows again.

For economic exploitation of this plant, it is necessary to establish an annual and systematic cultivation system without changing the organoleptic properties of its essential oil. Experiments have shown that the aromatic plants hydroponically cultivated have higher productivity and, in addition, accumulate more essential oil per unit when compared with the plants cultivated in the field. Hydroponic techniques have been applied successfully in cultivation of herbs and medicinal plants. ${ }^{6-8}$ A hydroponic system provides some advantages, such as standardization of the production process and the ease with which plants can be handled on an industrial scale.

Targeting the economic use of "pataqueira", it was decided to subject the plant to a NFT (Nutrient film technique) hydroponic cultivation, ${ }^{9}$ similar to what is done with the cultivation of vegetables and to make comparative studies of plants obtained from naturally occurrence with the plants grown hydroponically. The aim of this paper is to present and discuss this comparative study.

\section{Materials and methods}

\section{Plant material}

Plants occurring naturally and plants produced hydroponically were used for this study (Figure 1) (Figire 2). The materials from young (seedlings from natural regeneration) and mature plants (PM) were collected in an Environmental Protection Area of the city of Belem, Para state, Brazil, March 2012. The place of occurrence of the plant was selected because we had already worked with their natural populations, whose oil composition was well known. Plants grown hydroponically $(\mathrm{PH})$ were produced and harvested in an experimental area of the Universidade Federal Rural da Amazonia (UFRA), located in Belem, July and September 2012. Plant samples (voucher MG 174901) were identified and deposited in the herbarium of the Museu 
Emilio Goeldi (MPEG), Belem city, Para state, Brazil.

The plants were dried by two ways:

i. Using aluminum trays at room temperature $\left(28^{\circ} \mathrm{C}, 75 \%\right.$ relative humidity) for 5 days.

ii. Using a fixed bed dryer $\left(50^{\circ} \mathrm{C}, 75 \%\right.$ relative humidity) for $60 \mathrm{~min}$.

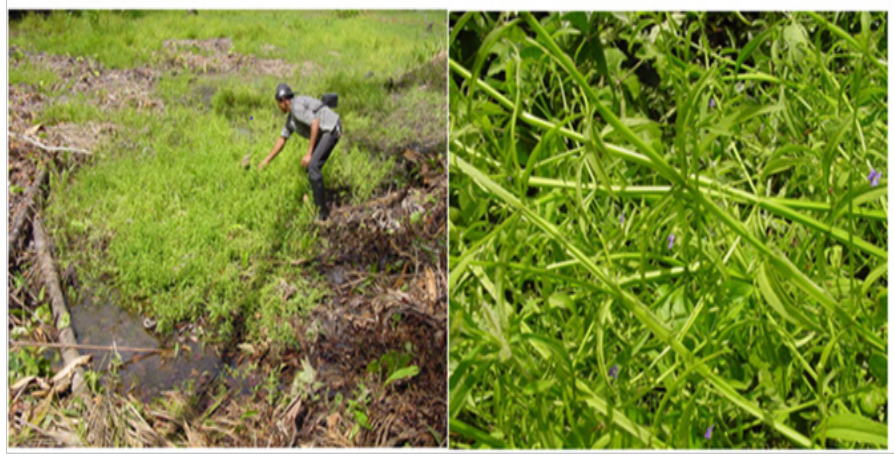

Figure I Pataqueira in natural environment.

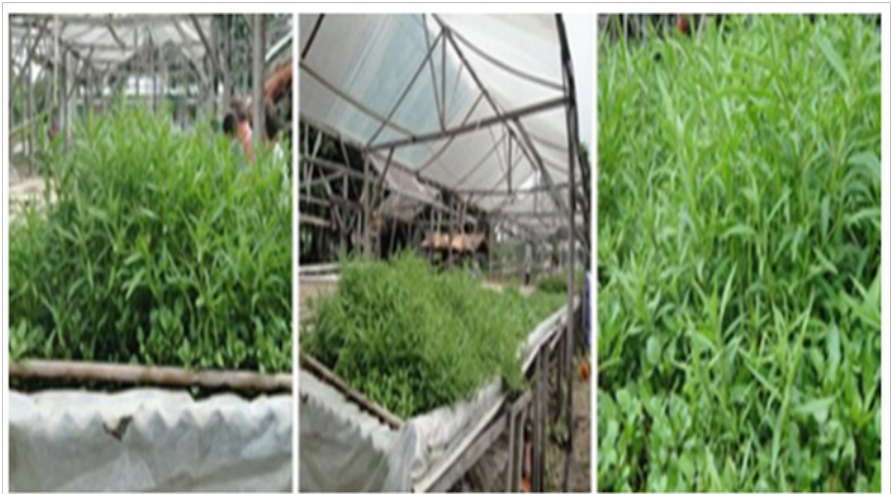

Figure 2 Pataqueira in hydroponic environment.

In the fixed bed dryer was adapted a centrifugal blower and a pair of electrical resistances with power controller, for the purpose of inflating the air into the system and keep it heated at a temperature of $50^{\circ} \mathrm{C}$. Then, fresh and dried plants obtained from the natural environmental (PNf and PNd) and produced by hydroponics (PHf, $\mathrm{PHd}$ and $\mathrm{PHb}$ ) were hydrodistilled in a Clevenger-type apparatus $(100 \mathrm{~g}, 3 \mathrm{~h})$, separately. The resulting oils were dried over anhydrous sodium sulfate and the yields calculated on the basis of the plant dry weight. The moisture content of the samples was calculated after phase separation in a Dean-Stark glass apparatus (5 g, 60min), using toluene.

\section{Hydroponic cultivation}

Seedlings $(15 \mathrm{~cm}$, on average) from a wild population of "pataqueira" were used and the experiment was carried out in a homemade greenhouse of UFRA, Belem, Brazil. A NFT hydroponic system with a reservoir of 1,000 liters of nutrient solution was used. ${ }^{9}$ In the NFT cultivation method, the roots of the plants remained in a shallow stream of recirculation nutrient solution. This solution was discharged into the upper part of a sloping channel tile (fiber-cement) covered with a polyethylene film containing the plants. At the lower part of the channel tile, the solution was conducted back to the reservoir by gravity and pumped again for circulation in the plants. The nutrient solution $(\mathrm{g} / 1000 \mathrm{~L})$ has been proposed by Furlani et al., ${ }^{10}$ containing calcium nitrate $(750 \mathrm{~g})$, potassium nitrate $(500 \mathrm{~g})$, monoammonium phosphate $(150 \mathrm{~g})$, magnesium sulfate $(400 \mathrm{~g})$, copper sulfate $(0.15 \mathrm{~g})$, zinc sulfate $(0.5 \mathrm{~g})$, manganese sulfate $(1.5 \mathrm{~g})$, boric acid $(1.5 \mathrm{~g})$, sodium molybdate $(0.15 \mathrm{~g})$ and ferrilene 6 (Fe-EDDHA chelate) $(30 \mathrm{~g})$. The nutrient solution has flowed in the channel bed at a constant rate of $800 \mathrm{ml} / \mathrm{min}$. The supply of nutrient solution was $6 \mathrm{am}$ until $9 \mathrm{pm}$, at intervals of $15 \mathrm{~min}$ controlled by a timer, average temperature of $27^{\circ} \mathrm{C}$, and with reduced light intensity by $30 \%$. The solution was periodically examined and, when necessary it was adjusted to maintain the ratio of the nutrient elements. The $\mathrm{pH}$ value was $6.0 \pm 1.0$ and the electrical conductivity was adjusted to $1.6 \pm 0.4 \mathrm{~m} \mathrm{~S} / \mathrm{cm}$.

\section{Plant tissue chemical analysis}

Chemical analysis of plant tissue of the plant was taken in the Laboratorio de Solos da EMBRAPA Amazonia Oriental, Belem, PA, using routine techniques for the following elements: $\mathrm{N}$ (Kjeldahl, semi-micro method), P (colorimetric method, UV/Vis 660nm), K (atomic emission spectrometry, flame photometer), $\mathrm{Ca}, \mathrm{Mg}, \mathrm{Cu}$, $\mathrm{Zn}, \mathrm{Fe}$ and $\mathrm{Mn}$ (atomic absorption spectroscopy, atomic absorption spectrophotometer). The analysis was triplicate.

\section{Oil-composition analysis}

The oils were analyzed qualitatively on a THERMO DSQ II GC/MS instrument under the following conditions: DB-5ms $(30 \mathrm{~m} \times 0.25 \mathrm{~mm} ; 0.25 \mu \mathrm{m}$ film phase thickness) fused-silica capillary column; programmed temperature, $60-240^{\circ} \mathrm{C}\left(3^{\circ} \mathrm{C} / \mathrm{min}\right)$; injector temperature, $250^{\circ} \mathrm{C}$; carrier gas, helium adjusted to a linear velocity of $32 \mathrm{~cm} / \mathrm{sec}$ (measured at $\left.100{ }^{\circ} \mathrm{C}\right)$; injection type, splitless $(2 \mathrm{~L}$ of a 1:1000 hexane solution); split flow was adjusted to yield a 20:1 ratio; septum sweep was a regular $10 \mathrm{~mL} / \mathrm{min}$; EIMS electron energy, $70 \mathrm{eV}$; temperature of the ion source and connection parts, $200^{\circ} \mathrm{C}$. Regarding the volatile constituents, the quantitative data were obtained by peakarea normalization using a FOCUS GC/FID operated under similar conditions of the GC-MS system, except for the carrier gas, which was nitrogen. GC run was replicated three times. The retention index was calculated for all the volatiles constituents using an $n$-alkane $\left(\mathrm{C}_{8}\right.$ $\mathrm{C}_{32}$, Sigma-Aldrich) homologous series. ${ }^{11}$

\section{Results and discussion}

Table 1 shows the chemical analysis of plant tissue obtained from the natural source and produced by hydroponics. The percentage of copper, manganese, zinc, iron, nitrogen, phosphorus, potassium, calcium and magnesium were determined. The analysis of elements helped in the selection of plant nutrition solution during the hydroponic cultivation. ${ }^{10}$

The oils of the fresh plants and subjected to hydroponic cultivation were analyzed by GC and GC-MS. Individual components were identified by comparison of both mass spectrum and GC retention data with authentic compounds, which were previously analyzed and stored in the data system, as well as with the aid of commercial libraries containing retention indices and mass spectra of volatile compounds commonly found in essential oils. ${ }^{12,13}$ In total, seventeen constituents were identified in the oils, which comprise about $96.0 \%$ of the total composition. They were listed in Table 2. It was not surprise for us that the three major constituents of the oils were methylthymol (PNf, 40.0\%; PHf, 33.8\%), thymol (PNf, 38.5\%; PHf, 32.1\%) and $\alpha$-phellandrene (PNf, 12.9\%; PHf, 25.0\%), because another samples from the same collection site previously had shown the same results. ${ }^{4,5}$ 
The constituents of the oils obtained from the plants of natural origin (PNd) and hydroponically cultivated (PHd), both plants dried at room temperature, as well as the components of the oil obtained from the plant dried at fixed bed dryer ( $\mathrm{PHb})$, were listed in Table 3.

Table I Elemental composition of C. scoparioides plant tissue

\begin{tabular}{llll}
\hline \multirow{2}{*}{ Egetal tissue } & Elements & \multicolumn{2}{c}{ Samples } \\
\cline { 3 - 4 } & & PNf & PHf \\
\hline & $\mathrm{Cu}(\mathrm{mg} / \mathrm{kg})$ & 5.5 & 9.2 \\
& $\mathrm{Mn}(\mathrm{mg} / \mathrm{kg})$ & 164.7 & 188.3 \\
Micronutrient & $\mathrm{Zn}(\mathrm{mg} / \mathrm{kg})$ & 60.6 & 60.6 \\
& $\mathrm{Fe}(\mathrm{mg} / \mathrm{kg})$ & 714.2 & 471.9 \\
& $\mathrm{~N}(\mathrm{~g} / \mathrm{kg})$ & 24.3 & 31.4 \\
& $\mathrm{P}(\mathrm{g} / \mathrm{kg})$ & 4.2 & 5.3 \\
& $\mathrm{~K}(\mathrm{~g} / \mathrm{kg})$ & 11.0 & 45.6 \\
& $\mathrm{Ca}(\mathrm{g} / \mathrm{kg})$ & 4.3 & 6.5 \\
& $\mathrm{Mg}(\mathrm{g} / \mathrm{kg})$ & 6.8 & 12.2 \\
\hline
\end{tabular}

PNf, fresh plants from natural origin; $\mathrm{PHf}$, fresh plants from hydroponics

Table 2 Oil composition (\%) of C. scoparioides from natural origin and produced hydroponically - fresh plant

\begin{tabular}{|c|c|c|c|}
\hline Constituents & $\mathbf{R I}$ & PNf & PHf \\
\hline$\alpha$-pinene & 935 & 0.3 & 0.3 \\
\hline 3-octanone & 984 & 1.2 & 1.2 \\
\hline$\alpha$-phellandrene & 1006 & 12.9 & 25.0 \\
\hline p-cymene & 1025 & 0.9 & I.I \\
\hline$\gamma$-terpinene & 1057 & 0.3 & 0.3 \\
\hline p-cymenene & 1089 & 0.2 & 0.1 \\
\hline linalool & 1100 & 0.3 & 0.2 \\
\hline p-cymen-8-ol & 1180 & 0.7 & 0.3 \\
\hline trans-p-mentha-I (7),8-dien-2-ol & 1189 & 0.2 & \\
\hline methylthymol & 1245 & 40.0 & 33.8 \\
\hline thymol & 1295 & 38.5 & 32.1 \\
\hline carvacrol & 1297 & 0.2 & \\
\hline eugenol & 1355 & & 0.3 \\
\hline thymol acetate & 1358 & & 0.4 \\
\hline$\alpha$-zingiberene & 1493 & 0.9 & 0.8 \\
\hline$(E, E)$-farnesene & 1508 & & \\
\hline (E)-nerolidol & 1563 & & 0.1 \\
\hline Aromatic monoterpenes & & 80.5 & 67.8 \\
\hline Cyclohexadiene monoterpenes & & 13.2 & 25.3 \\
\hline Other & & 2.9 & 2.9 \\
\hline Total & & 96.6 & 96.0 \\
\hline
\end{tabular}

$\mathrm{RI}$, retention index (on DB-5ms column); PNf, fresh plants from natural origin; $\mathrm{PHf}$, fresh plants from hydroponics
Table 3 Oil composition (\%) of C. scoparioides from natural origin and produced hydroponically - dried plant.

\begin{tabular}{|c|c|c|c|c|}
\hline Constituents & $\mathbf{R I}$ & PNd & PHd & PHb \\
\hline$\alpha$-pinene & 935 & 0.4 & 0.2 & 0.2 \\
\hline 3-octanone & 984 & 1.8 & 1.8 & 1.8 \\
\hline$\alpha$-phellandrene & 1006 & 24.8 & 20.0 & 17.7 \\
\hline p-cymene & 1025 & I.I & 1.2 & 1.2 \\
\hline$\gamma$-terpinene & 1057 & 0.3 & 0.4 & 0.4 \\
\hline p-cymenene & 1089 & 0.1 & 0.2 & 0.1 \\
\hline linalool & 1100 & 0.1 & 0.3 & 0.3 \\
\hline p-cymen-8-ol & 1180 & 0.3 & 0.6 & 0.7 \\
\hline$\alpha$ - terpineol & 1186 & 0.1 & 0.1 & 0.1 \\
\hline methylthymol & 1245 & 20.3 & 27.2 & 27.4 \\
\hline thymol & 1295 & 47.8 & 43.8 & 45.2 \\
\hline carvacrol & 1297 & 0.1 & 0.3 & \\
\hline eugenol & 1355 & 0.3 & 0.4 & 0.5 \\
\hline thymol acetate & 1358 & 0.1 & 0.5 & 0.4 \\
\hline$\alpha$-zingiberene & 1493 & 0.1 & 0.1 & 0.5 \\
\hline$(E, E)$-farnesene & 1508 & & 0.1 & \\
\hline (E)-nerolidol & 1563 & & 0.1 & 0.1 \\
\hline Aromatic monoterpenes & & 69.8 & 73.8 & 75.0 \\
\hline Cyclohexadiene monoterpenes & & 25.1 & 20.4 & 18.1 \\
\hline Other & & 2.8 & 3.1 & 3.5 \\
\hline Total & & 97.7 & 97.3 & 96.6 \\
\hline
\end{tabular}

$\mathrm{RI}$, retention index (on DB-5ms column); $\mathrm{PNd}$, dried plants from natural origin; $\mathrm{PHd}$, dried plants from hydroponics; $\mathrm{PHb}$, dried plants from fixed bed dryer

Conobea scoparioides showed excellent adaptation to the NFT hydroponic cultivation system. The species doubled in size after the first two months of cultivation, reaching $30 \mathrm{~cm}$ and in four months it was growing to $85 \mathrm{~cm}$. The growth of the root system was so abundant after four months that it allowed us to perform the first cut from the aerial parts of the plant. With spacing of $20 \mathrm{~cm}$ between the plants, another positive aspect was the extraordinary branching of the plant, which enabled a yield of fresh weight exceeding $4 \mathrm{~kg} / \mathrm{m}^{2}$. After the first harvest, the plant resumes the growth as observed in its natural habitat. The increase in biomass was reduced at six months, which means that the best cut time is every four months and whose general rule could be of three annual cuts.

In the NFT hydroponic system, the plants were healthier than in their natural habitat. Chemical analysis of plant tissues that was hydroponically growing showed values of $\mathrm{N}, \mathrm{P}, \mathrm{K}, \mathrm{Ca}, \mathrm{Mg}, \mathrm{Cu}$ and Mn significantly higher, as can be seen in Table 1. On the other hand, the Fe content was strongly reduced, which means that the iron-rich soil of the Amazon is not very suitable for the cultivation of the plant. Based on the results, we have the hypothesis that the poor soil of the Amazon region must be also a barrier for the plant growth during the dry season and not just a water stress problem. A clear example was the analysis of the soil where the plant was collected, whose 
high concentration of Fe $(1086.4 \mathrm{mg} / \mathrm{kg})$ seems to affect toxically the species. The plant kept in hydroponics during the dry season was healthy throughout their growth phase. With these results, it was concluded that the hydroponic cultivation is a real alternative to the economic exploitation of the essential oil of this aromatic herbaceous plant.

The water content in the plants of "pataqueira" which grew at aqueous environment is remarkably high (about 90\%). This water excess complicates the plant distillation process, producing low oil yield. The distillation process is most effective when the water content of the plant is reduced to about $30 \%$. The oil yield of the plant from the natural environment (PNd) was $2.2 \%$, when it was dried at ambient temperature for five days. The oil yield of the plant produced by hydroponics (PHd) was 3.2\%, under the same drying conditions or using a fixer bed dryer. It was estimated that $1000 \mathrm{~m}^{2}$ of hydroponic cultivation of $C$. scoparioides can produce $128 \mathrm{~kg}$ of oil in $4 \mathrm{months}$, or about $380 \mathrm{~kg}$ of oil per year in three annual crops.

The oil composition of "pataqueira" did not change with respect to its volatile constituents, but the percentage of the main compounds varied between the plants from natural occurrence and produced by hydroponic treatment. In the oils of plants grown hydroponically (PHf) and harvested from the wild (PNf), the aromatic monoterpenes are the most representative, varying from $67.8 \%$ to $80.5 \%$ (Table 2). The aromatic monoterpenes are followed by cyclohexadiene-type monoterpenes, varying from $13.2 \%$ to $25.3 \%$ in an opposite way, i.e. from the natural plants to the plants grown hydroponically. The main constituents of the oils were methylthymol (PNf, 40.0\%; PHf, 33.8\%), thymol (PHf, 38.5\%; PHf, 32.1\%) and $\alpha$-phellandrene (PNf, 12.9\%; PHf, $25.0 \%$ ). Comparing the two oils we can see that the value of $\alpha$-phellandrene doubled in the plant cultivated by hydroponics while the values of methylthymol and thymol were slightly reduced (Table 2 ). One would expect an increase in the content of $\alpha$-phellandrene in the young plants cultivated by hydroponics, considering that this constituent is a precursor (also $\gamma$-terpinene) of thymol and methylthymol in the biogenetic process of the plant. ${ }^{14-16}$ The plant generated by hydroponics was younger (4months of cropping) than the plant collected in their natural habitat and its enzymatic system must have influenced these changes.

The main constituents of the oils from the plants of natural origin $(\mathrm{PNd})$, hydroponically cultivated $(\mathrm{PHd})$ and dried at fixed bed dryer $(\mathrm{PHb})$ were thymol (PNd, 47.8\%; PHd, 43.8\%; $\mathrm{PHb}$, 45.2\%), methylthymol (PNd, 20.3\%; PHd, 27.2\%; PHb, 27.4\%) and $\alpha$-phellandrene (PNd, 25.0\%; PHd, 20.0\%; PHb, 17.7\%) (Table 3 ). Comparing the oils, it can be seen that the percentage of thymol remained almost unchanged, there was a small increase in the content of methylthymol while the amount of $\alpha$-phellandrene was reduced by about $20 \%$. The reduction of $\alpha$-phellandrene content, after the plant be subjected to the drying process, was already expected. The vapor pressure of this constituent is higher in comparison than methylthymol and thymol, particularly in young plants.

In the biosynthetic pathway of monoterpenes, neryl and geranyl pyrophosphate are the natural substrates for the monoterpene synthases. All enzymes of this class can efficiently utilize them as precursors for the production of various metabolites, such as $\gamma$-terpinene, $\alpha$-phellandrene, $p$-cymene, thymol, methylthymol and carvacrol, which are structurally related and occurs in the oil of C. scoparioides (Figure 3). The co-occurrence of the aromatic monoterpenes ( $p$-cymene, thymol, carvacrol and derivatives) with the cyclohexadiene-type monoterpenes ( $\gamma$-terpinene and $\alpha$-phellandrene), structurally related, suggests the possibility that these metabolites must be biogenetically related. Incorporation studies of ${ }^{14} \mathrm{CO}_{2}$ in the volatile terpenoids from Thymus vulgaris cuttings, showed strong evidence that thymol is biosynthesized by aromatization of $\gamma$-terpinene (also $\alpha$-phellandrene) to $p$-cymene, followed by hydroxylation process. ${ }^{14-16}$ These findings also support the interpretation of the results obtained with the analysis of the oils of $C$. scoparioides, from natural origin and hydroponic cultivation.

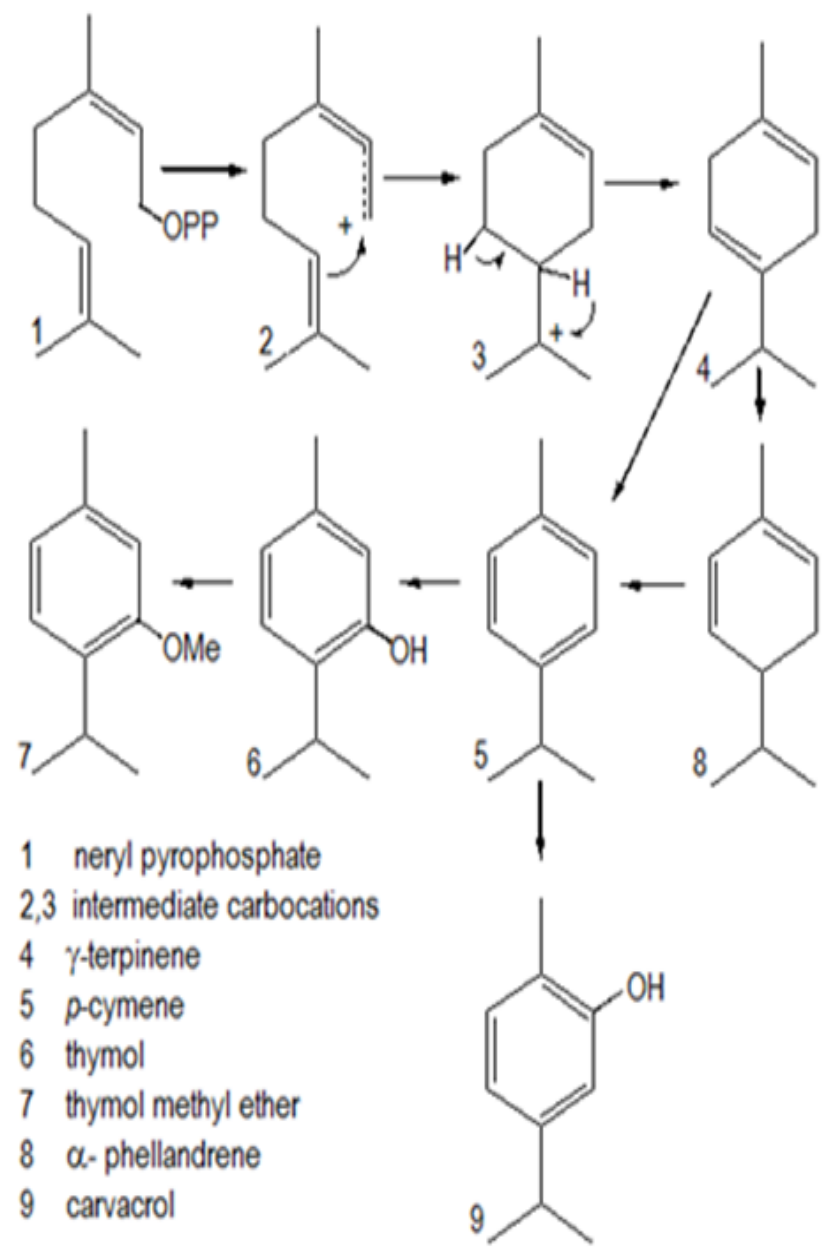

Figure 3 Main constituents of the oil from C. scoparioides and its biosynthetic relationship, originating from the precursor neryl pyrophosphate.'

In general, the essential oil odor might be a result of the balance between its components. Changes in composition might impact the quality of the final product. When the contents of the main constituents (thymol, methylthymol and $\alpha$-phellandrene) changed in the oils of plants from natural origin and produced by hydroponics, this could signify an impact in the quality oil. In practical terms, the highest content of $\alpha$-phellandrene for oil distilled from plants grown hydroponically resulted in a product with less odor thyme, as that provided by thymol. The oil produced by hydroponics showed a pleasant and pronounced fresh-citrusy and peppery-woody odor, due to the increase of the content of $\alpha$-phellandrene. The oil of "pataqueira" is not yet normally commercialized and this slight change can be beneficial to its economic exploitation. 


\section{Conclusion}

Seedlings of $C$. scoparioides showed excellent adaptation to the NFT hydroponic cultivation system. The plant increased four times in size after 4 months of cropping. In this period, using the spacing of $20 \mathrm{~cm}$ between plants was possible to produce a fresh biomass with yield of $4 \mathrm{~kg} / \mathrm{m}^{2}$. The values of $\mathrm{N}, \mathrm{P}, \mathrm{K}, \mathrm{Ca}$ and $\mathrm{Mg}$ were increased significantly in the plant when compared with those collected in the natural environment, which resulted in a more healthy and robust crop. The oil yield obtained from the hydroponic cultivation was increased in $1.0 \%$ and its volatile composition showed a slight quantitative variation. The balance between the main constituents, thymol, methylthymol and $\alpha$-phellandrene, was remained in the range of $90.0 \%$, but the content of $\alpha$-phellandrene was increased in relation to other two metabolites. The oil distilled from plants grown hydroponically resulted in a product with less odor thyme, replaced by a fresh-citrusy and peppery-woody note.

\section{Acknowledgements}

The authors are grateful to Bionorte/CNPq Program and FAPESPA/ PA for the financial support and to Mr F. C. Nascimento for the plant collection.

\section{Conflict of interest}

The author declares no conflict of interest.

\section{References}

1. http://www.tropicos.org/NAME/29200721

2. Cruz GL. Dicionario das plantas uteis do Brasil, Editora Civilizacao Brasileira, Rio de Janeiro; 1979.

3. Rodrigues RM. Flora da Amazonia, Editora Cejup, Belem; 1989.

4. Maia JGS, Zoghbi MGB, Andrade EHA, et al. Essential oils from Conobea scoparioides (Cham. \& Schltdl.) Benth. Flav Fragr J. 2000;15(6):413-414.

5. Rebelo MM, Silva JKR, Andrade EHA, et al. Antioxidant capacity and biological activity of essential oil and methanol extract of Conobea scoparioides (Cham. \& Schltdl.) Benth. J Braz Chem Soc. 2009;20(6):1031-1035.
6. Mairapetyan SK. Aromatic plant culture in open-air hydroponics. Acta Hort. 1999;502:33-36.

7. Karioti A, Skaltsa H, Demetzos C, et al. Effect of nitrogen concentration ot the nutrient solution on the volatile constituents of leaves of Salvia fruticosa Mill. In solution culture. J Agric Food Chem. 2003;51(22):6505-6508.

8. Economakis CD, Karioti A, Skaltsa H, et al. Effect of solution conductivity on the volatile constituents of Origanum dictamnus L. In nutrient film culture. J Agric Food Chem. 2005;53(5):1656-1660.

9. Cooper A. The ABC of NFT, Nutrient Film Technique - the world's first method of crop production without a solid rooting medium. London: Casper Publications Pty Ltd; 2002.

10. Furlani PR, Silveira LCP, Bolonhezi D, et al. Cultivo hidropônico de plantas, Boletim Tecnico IAC $n^{\circ} 180$. Sao Paulo: Instituto Agronomico de Campinas; 1999.

11. Van Den Dool H, Kratz PDJA. J Chromatogr A. 1963;11:463.

12. NIST (National Institute of Standards and Technology). PC version 2.0d NIST/EPA/NIH Mass Spectral Database Gaithersburg: U.S. Department of Commerce; 2005.

13. Adams RP. Identification of Essential Oil Components by Gas Chromatography/Mass Spectrometry. 4th ed. Illinois, USA: Allured Publ Corp; 2007.

14. PouloseAJ,CroteauR.Biosynthesisofaromatic monoterpenes:conversion of gamma-terpinene to $p$-cymene and thymol in Thymus vulgaris L. Arch Biochem Biophys. 1978;187(2):307-314.

15. Poulose AJ, Croteau R. $\gamma$-Terpinene synthetase:a key enzyme in the biosynthesis of aromatic monoterpenes. Arch Biochem Biophys. 1978;191(1):400-411.

16. Bohlmann J, Meyer-Guaen G, Croteau R. Plant terpenoid synthases:molecular biology and phylogenetic analysis. Proc Natl Acad Sci USA. 1998;95(8):4126-4133. 